\title{
Modeling the International Technology Transfer Process in Construction \\ Projects: Evidence from Thailand
}

\author{
Tanut Waroonkun and Rodney A. Stewart \\ T. Waroonkun \\ Griffith School of Engineering, Griffith University, PMB 50 GCMC, QLD 9726, Australia \\ t.waroonkun@griffith.edu.au \\ R. A. Stewart $(\bowtie)$ \\ Griffith School of Engineering, Griffith University, PMB 50 GCMC, QLD 9726, Australia \\ r.stewart@griffith.edu.au
}

\begin{abstract}
Many developing and newly industrialized countries lack the technical and management capabilities to undertake large and/or complex infrastructure projects. In an effort to more rapidly develop their infrastructure, economies and living standards, many have embarked on a series of international Technology Transfer (TT) initiatives within the construction and other industries. However, these initiatives have not immediately translated into enhanced capabilities and competitiveness within host country firms, resulting in a sustained reliance on foreign firms. In an attempt to improve rates of TT in developing countries, this article proposes a conceptual model for international TT that accommodates the numerous factors believed to impact on the processes effectiveness and derived outcomes. Utilizing the results from a questionnaire survey of 162 industry professionals from Thailand, an international TT model including the significant factors which impact on the TT process and the degree of value added from it, was formulated through exploratory and confirmatory factor analysis. Moreover, the significance of direct and indirect interrelationships between model factors was determined through structural equation modeling. This model included four process enablers, namely, government influence, transferee characteristics, transferor characteristics and relationship building, and one outcome factor named TT value added. Building relationships (i.e. trust, understanding and communication) between the transferor and transferee was determined to be the key predictor of TT-induced value creation for the host construction sector.
\end{abstract}

Keywords: Technology transfer, developing countries, Thailand, structural equation model 


\section{Introduction}

International TT continues to be a key stimulant to industrialization and economic growth in developing countries, particularly in the fast growing Asian countries such as Thailand, Sri Lanka, China, Myanmar, etc. (Devapriya and Ganesan, 2002; Ganesan and Kesley, 2006; Marton, 1986; Saad et al., 2002; San, 2004; Schnepp et al., 1990). Several researchers have defined the TT term differently due to their individual fields of study. Chacko (1986) described TT in a scientific manner as converting physical/mental matter/energy into directly usable alternate form(s), and transfer means from one pocket into another pocket. Williams and Gibson (1990) defined TT as the shared responsibility between the source and the destination by ensuring that the technology is accepted, or at least understood, by someone who has the knowledge and the resources to apply and/or use the technology. In the construction sector, Simkoko (1992) attempted to build on this definition by identifying individual construction resources, as either materials or permanent equipment (e.g. steel beam, elevators, material) or construction-applied resources (e.g. information, skill). For the purpose of this study, international TT has been defined as when all types of knowledge relating to the construction field (e.g. design, construction process, material use, equipment utilization, etc.) are transferred from a foreign party (transferor) to a host party (transferee) that arranges to receive it. In this research, the transferee refers only to Thai Architectural, Engineering and Construction (AEC) firms and the transferor refers to the foreign AEC firms working with Thai firms to procure projects. As expected, transferor firms had origins in developed nations such as the United States, Japan, Germany, United Kingdom, France, Australia, etc.

Over the last twenty years, numerous researchers have attempted to examine and/or model the international TT process (e.g. Calantone et al., 1990; Lin and Berg, 2001; Malik, 2002). A large portion of these studies were predominately focused on the business and manufacturing sectors. Some of these empirical and qualitative studies resulted in the development of a framework or model of the international TT process. However, few of these models were reinforced by robust empirical data analysis and none failed to link the international TT process enablers to the wide spectrum of identifiable outcomes. Moreover, none of these existing models can be immediately adopted to comprehensively explain interactions between TT process enablers and outcome factors in the construction context. In an attempt to develop a more comprehensive TT 
model, that quantifies causal pathways between macro and micro influential TT enabling factors to derived outcomes for the local construction sector, an international TT model was conceptualized and operationalized. Whilst the construct descriptions supporting the conceptual model are broad enough to explain TT across a wide range of industry sectors, the intricacies of the construction sector are accommodated through variables which attempt to explain industry specific issues.

Numerous factors impact on the performance of the TT process and ultimately the degree of value added to the local construction sector. This is especially true in firms from the construction sector in developing countries, who in recent years assumed that they could more rapidly improve their management and technical capabilities through TT initiatives with foreign firms (San, 2004). These factors can be broadly defined as enablers and include the transfer environment, learning environment, transferor characteristics and transferee characteristics. The performance of and interaction between these enablers can influence the degree of value added to the host construction sector, in areas such as economic advancement, knowledge advancement and project performance. The developed international TT model presented herein illustrates the connections between TT enablers and outcome factors. The following section summarizes the undertaken scholarly review and critique on existing TT models reported in the literature.

\section{Literature Review}

Whilst many existing TT models were developed for the business and manufacturing sectors, the author is not aware of any comprehensive TT model developed specifically for modeling international TT on construction projects. Such a model would need to be developed through a process of justifying, grouping, linking and refining factors established across a number of different industry sectors. Thus, the aim of this section is to examine existing models developed across all industry sectors with the view to develop a conceptual TT model, which is specifically designed for the construction sector (Calantone et al., 1990; Lin and Berg, 2001; Malik, 2002; Simkoko, 1992; Wang et al., 2004). The first two discussed models were particularly helpful when formulating the overall structure of the conceptual model. The next three models reviewed assisted with the identification of the main TT factors which impact on the TT process and the 
value it generates. Each of these models and their limitations with respect to the objectives of this study are presented. It should be noted that only complete TT models are reviewed in this section. Arguments for the inclusion of individual variables which constitute conceived TT enabling and outcome constructs or factors are presented in the next section.

Malik (2002) produced a TT model for intra-firm technology transfer. The 'broadcasting analogy' was adapted into the Malik (2002) model where by the technology to be transferred is assimilated to be a radio transmitted message. This message is transferred from a transmitter (transferor) to a receiver (transferee). The strength of this transmitted message is affected by both factors likely to help and factors likely to inhibit. Whilst this model comprehensively examines the interactive nature of the communication processes within a single organization, there are many different considerations when transferring technology to an outside operator. For instance, the intra-firm model does not closely examine the issues associated with the intent of the transferor to protect its core technology from its competitors and the possibility of differing project objectives. This model may also have biased empirical supportive evidence because it was based on responses from only one manufacturing company. To achieve a more reliable model, testing should have been carried out with several different firms from a range of different industries. Moreover, influential factors have been identified but their impact on outcomes requires closer examination. Furthermore, the factors likely to help and likely to inhibit could have been categorized more accordingly into transmitter and receiver elements as they mostly represent personal characteristics of the technology provider and receiver, respectively.

Calantone et al. (1990) developed a comparative marketing framework for international TT based on concepts formulated by Boddewyns' comparative marketing research (Boddewyn, 1966; Boddewyn, 1981). Their study strives to apply the comparative marketing principles stated by Boddewyn to the field of international TT and also incorporates other empirical studies. This framework presents a system made up of five elements, including, environment, actors, structure, process and functions. The framework is designed such that interactions between elements feed back to environmental variables (e.g. economic policies). For instance, if the process was highly unsuccessful, economic policies may be introduced which discourage 
participation in TT programs. These factors will then again impact on the transfer process creating a continuous cycle of international TT development. Whilst this framework seeks to describe the feedback of international TT factors, it fails to incorporate indicators for identifying the outcomes of TT initiatives. Furthermore, the model is extremely complex in design and has not been empirically verified through a robust statistical analysis regime. Also, whist the model includes a number of factors which could be adapted for utilization in the construction context, the model as a whole is largely relevant in the marketing and logistics sector only. Nonetheless, there were several important factors that have been identified that were adopted from this framework to produce the conceptual model for international TT in construction projects.

Simkoko (1992) conducted research focused on TT in the construction industry of developing countries. Competence development through TT was closely examined to determine the influential factors that impact on this process. This research was based on case studies of 12 international construction projects in the developing countries of Africa, South America and Asia in 1987 and 1988. The selection criteria for the projects to be investigated were as follows: local firm involvement; technology acquisition objective explicitly or implicitly expressed by clients; and projects completed recently or currently under construction. The objective of this research was to examine the impact of TT programs and other internal and external environment factors on construction project performance. Simkoko identified seven factors which impact on the construction project delivery process, namely: (1) project delivery system; (2) project management teams; (3) transfer programs: (4) client characteristics; (5) project characteristics; (6) design and construction technologies; and (7) project performance. Analysis on the relationship between these seven factors was undertaken at both qualitative and statistical levels (i.e. Chi-squared tests and ranked correlation coefficients). This research represents the only available international TT model tailored for the construction sector. However, the study only investigates the development of technological and management practices in the local industry, rather than attempting to model the TT enabling process. The model does not examine the impact of the transferee and transferor in the process and also the full value added from implementing TT initiatives other than competence development. Nonetheless, the model has given some insight into possible enabling and outcome factors to be used for the development of the herein presented conceptual model for international TT in construction projects. Although this research was focused on competence development of 
local firms, rather than the entire value added from the TT process, there is a broad range of competence development benefits which could cover some aspects of the overall value added through TT initiatives.

Wang et al. (2004) conducted a study primarily concerned with the transfer of knowledge from a multinational company to a subsidiary. This model was developed from semi-structured interviews with 62 multinational companies operating in China and identified two stages in the transfer process. The first stage is focused on the parent's contribution of knowledge (i.e. capacity and willingness to transfer) and the second stage on the subsidiary's acquisition of knowledge (i.e. capacity and intent to learn). The main concerns with this research pertain to its foundation being based on case studies of multinational companies that are generalized to theoretical propositions and not to the general population. Another weakness is that the intensive use of empirical evidence may have been produced from theory that is overly complex rather than parsimonious. To counteract this, quantitative analysis methods such as regression analysis could have been employed. The Wang model also is limited by the scope of the TT process that was examined. Scope was confined to the amount of knowledge that a subsidiary of a multinational company acquires as a result of the transferor and transferee characteristics. Although these two enabler constructs are examined in sufficient detail the model fails to examine other influential factors on the TT process. Moreover, outcome factors beyond the attainment of knowledge gained from the TT process (e.g. economic advancement) was not explored.

The last reviewed TT model was created by Lin and Berg (2001). They undertook an exploratory study into the effects of cultural difference on TT projects in Taiwanese manufacturing firms. Three groups of factors were investigated in this study: (1) nature of technology; (2) previous international experience; and (3) the cultural difference between the technology provider and receiver. These factors were investigated to determine their individual and combined impact on the effectiveness of the TT process. The TT effectiveness factor was concerned with measuring final technical performance. Whilst this study explores the valid concept that cultural differences can significantly impact on TT effectiveness, only two firms were used to confirm this hypothesis, which may have resulted in biased empirical findings. Additionally, the research identifies only three sets of factors that influence the TT process. For the construction industry this does not 
sufficiently describe all of the influential enabling and outcome factors. Important influences such as government policy, mode of transfer, to name a few, have been neglected. Also, this study does not effectively describe the link between the TT process and the outcomes it may derive. Even so, an important conclusion made in this study was that TT research investigations should not be limited to only examining the direct effects of identified factors and associated variables. It is also important to examine causal interactions between factors to achieve an accurate representation of the TT process. The factors and associated variables identified in this investigation were utilized to develop the conceptual model for international TT in construction projects described next.

\section{Conceptual Model}

The development of the conceptual model for international TT in construction projects aims to capture all of the relevant factors that influence the effectiveness of the TT process and the resulting value added (Figure 1). These relevant factors have been adapted from the examined leading studies into the TT phenomenon with the objective to develop a model which explains the international TT process in construction projects. Through a process of categorizing variables taken from the previous studies and conceptualizing their relationship with one another in the construction context a number of factors were identified. The factors identified were classified as enabling and TT value added factors. The classification of variables resulted in five definable factors (constructs), namely, Transfer Environment, Learning Environment, Transferee Characteristics, Transferor Characteristics and TT Value Added. The structure and links between the model constructs have also been conceptualized based on some experiential understanding and therefore require testing to confirm their appropriateness and validity. The hypothesized causal path between each enabling and the outcome factor is represented by the arrows. The literature provided sufficient evidence for the illustrated links shown in Figure 1, with the exception of two: (1) Transfer Environment $\rightarrow$ Transferor Characteristics; and (2) Transfer Environment $\rightarrow$ Transferee Characteristics. These links were insufficiently supported in the literature and therefore their validity was closely examined in the empirical study. These links have been largely conceptualized from an understanding of the international TT process and AEC sector. For example, the impact of the Transfer Environment onto Transferee Characteristics is one such link 
that has good theoretical background as it is likely that variables relating to the complexity of technology and government policy will influence the intent of the transferee to adopt new technology. The following sections describe the literature reinforcement for including each variable in the above mentioned enabling and outcome factors. A summary of these factors and their associated variables are presented in Table 1.

\section{(INSERT FIGURE 1)}

Figure 1 Conceptual model for international TT in construction projects

\section{Transfer environment}

The transfer environment is focused at the macro level of a country and its respective AEC sector, and is predominately concerned with the impact of country and project related factors on the TT process. This factor includes four sub-factors namely, the complexity of construction technology utilized by the transferor, mode of transfer, government policy and enforcement practices. Firstly, it is essential that the construction technology used on the project is more advanced than the current working practices of the host workers but not too advanced that they will be unable to embrace it on future projects (Simkoko, 1992). Secondly, the construction mode of transfer adopted on the project can influence the degree to which TT performs. Typically, construction projects incorporating TT are procured by turnkey systems, direct licensing agreements, management contracting or joint ventures. For the larger and/or complex TT projects, alternative modes may be adopted such as licensing-cum joint venture, turnkey-cum-licensing, etc. (Calantone et al., 1990). Finally, the host government's policies, regulations and enforcement practices can impact greatly on the effectiveness of TT initiatives, especially their international political system and domestic political structure (Calantone et al., 1990). Such policies should provide incentive to transferors to pro-actively disseminate knowledge to indigenous competitors. Inversely, the desire to acquire technology (i.e. technology itself) can be the driver for changing government policy in developing countries (Kumaraswamy and Shrestha, 2002; Ofori, 2000). 


\section{Learning environment}

The learning environment is concerned with the relationship and communication between the transferor and transferee, and the effectiveness of implemented transfer programs. Cultural characteristics and the distance between the technology provider and receiver is a major concern when managing international technology transfer (Fisher and Ranasinghe, 2001; Ganesan and Kesley, 2006; Kumaraswamy and Shrestha, 2002; Lin and Berg, 2001). For TT to function properly the organizations involved in the process should try to build a culture of mutual trust through effective communication between transferor and transferee (Black et al., 2000; Malik, 2002). This culture can only be established through strong commitment from the senior management teams of both the host and foreign organizations (Black et al., 2000; Devapriya and Ganesan, 2002). Moreover, an effective learning environment will be more likely to occur when either or both the transferor and transferee have been experienced in TT or partnering projects in the past (Black et al., 2000). Lastly, TT programs on construction projects, which are formally planned and managed (i.e. training times allocated, supervision specified, etc.), are more likely to transfer a greater degree of knowledge to the host workers (Saad et al., 2001; Simkoko, 1992).

\section{Transferor and transferee characteristics}

The remaining two enablers are related to the characteristics of the transferor (foreigner) and transferee (host). These enablers are concerned with the degree to which the characteristics of the transferor and transferee encourage the TT process (Kumaraswamy and Shrestha, 2002). Firstly, one of the essential elements to achieving successful TT is that the transferor is willing to transfer the appropriate technology and the transferee has every intention to adopt it (Ganesan and Kesley, 2006; Malik, 2002). Secondly, the degree of international experience of both the transferor and transferee and the nature of this experience can impact significantly on the TT process (Lin and Berg, 2001). Moreover, the capacity to transfer and adopt technology will also depend on each individuals existing knowledge base and the gap between this knowledge level and the level required to utilize the transferred technology (Saad et al., 2002; Wang et al., 2004). Lastly, the appropriateness of the transferor and transferees cultural traits (i.e. leadership style, ego, 
etc.) for working in a partnership should be determined prior to embarking on the TT process (Kumaraswamy and Shrestha, 2002; Fisher and Ranasinghe, 2001; Wang et al., 2004).

\section{TT-induced value creation}

The performance of, and interrelationship between, the above-mentioned TT enablers contributes to the degree of value added to the host AEC sector. The literature identifies three main areas (factors) where benefits may be derived from undertaking international TT initiatives: economic advancement, knowledge advancement and project performance. These factors are individually discussed in the following paragraphs.

One of the predominant reasons why governments in developing countries encourage international TT initiatives is because they believe such initiatives can improve their living standards and economic prospects (San, 2004; Schnepp et al., 1990). This bold objective can only be achieved if host workers and professionals perform at a higher level and become more competitive in the domestic and international market (Benedetto et al., 2003; Fisher and Ranasinghe, 2001). It should be noted here that economic advancement is a lagging factor that will typically occur in the long term once transferred knowledge has been absorbed and applied on a number of projects across the host country.

Beyond the quantitative economic benefits achievable from TT, host AEC firms may also experience knowledge advancement at the individual and organizational level (Gilbert and Cordey-Hayes, 1996). The initial outcome of TT programs is the transfer of implicit and tacit knowledge to the host workers. This knowledge, if accepted, should lead to improve working practices in the immediate term and hopefully become the norm over the long term.

It is generally accepted that the major objectives in construction projects are financial performance, schedule performance and quality performance (Chua et al., 1999). Improved performance in these key areas should result from effective technology transfer (Devapriya and Ganesan, 2002). This factor is concerned with the 
impact of TT programs on the performance of AEC projects. Specifically, this factor examines any improvements in the performance of financial, schedule and quality indicators.

Table 1 TT process enabling and value creation factors

(INSERT TABLE 1)

\section{Research Method}

Data collection for this study was undertaken with Thai construction professionals in the second quarter of 2005. The target group of respondents includes design and construction professionals from construction projects involving TT initiatives. This study only solicited the perceptions of transferees (Thai's) since TT initiatives are ultimately undertaken for the purpose of improving knowledge levels and enhancing the industry capacity of local (i.e. host) participants. Thus, individuals from host nations were considered to be the best respondents to evaluate the importance and effectiveness of variables pertaining to the TT process and the outcomes it can potentially generate. Justifiably, it was difficult to determine the exact population of potential respondents fitting the description for this target group. However, this process was achieved through examining lists obtained from the Engineering Institute of Thailand, Council of Architects, Thai Contractors Association and through consultation with senior academics in Bangkok and Chang Mai. It was estimated that a population of 1100 project professionals across 35 design and construction projects were involved in international TT activities. A target sample of 300 was randomly selected from this estimated population. In total, 300 surveys were distributed and 162 were returned, representing a response rate of 54 per cent. The questionnaire survey contained three distinct sections. The first section solicited descriptive statistics on the participating respondents and the past and present projects that they have been involved with where TT programs were integrated. This section enabled the establishment of a comprehensive respondent profile (i.e. experience, position description, etc.) and TT project profile (i.e. value, type, mode of transfer, etc.). Section two included questions relating to the enablers for successful TT, including: transfer environment; learning environment; transferor characteristics and transferee characteristics. Section three focused on measuring the outcomes of the TT process in the following categories: economic advancement, 
knowledge advancement; and project performance. Sections two and three contained a total of 29 questions representing all the variables in the conceptual model (Table 1). Respondents were requested to provide a rating for these variables in two separate columns (A and B) measured on a five-point Likert scale. Column A asked respondents for their opinion about statements related to TT, ranging from ' $1=$ strongly disagree' to ' 5 = strongly agree'. For example, the respondent was requested to rate whether they believed mutual trust will help to create a good relationship between the transferor and transferee. These results were used to determine the importance/significance of each variable. Column B sought to ascertain respondents' perception of the successfulness/effectiveness of TT factors in the construction environment, based on their experience. For example, respondents were requested to rate the effectiveness/success of 'mutual trust' on projects they have been involved in where international TT was incorporated. The scale of column B ranged from ' $1=$ strongly negative' to ' $5=$ strongly positive'. These results were essential for determining the effectiveness of TT in the Thai construction industry. Moreover, they enabled causal links between variables to be established. In summary, the data set obtained from Column A was utilized to ensure that variables were perceived to be sufficiently important to be considered as essential TT enabler and outcome variables (i.e. mean greater than three). The data set obtained from Column $B$ examined the successfulness/effectiveness of such TT variables and was utilized for evaluation purpose, formulating TT constructs and determining causal paths. Statistical techniques including exploratory factor analysis, confirmatory factor analysis and structural equation modeling were adopted for this purpose. A complete description of each of these stages is provided in later sections of this paper.

\section{Descriptive Statistics}

\section{Respondent Profile}

The respondents were classified into six position categories: project manager (16\%); site engineer (40\%); consulting engineer (16\%); construction manager/foreman (16\%); architect (11\%); and other (1\%). The type of organization they were employed in included: main contractor (43\%); sub-contractor (20\%); consultant (35\%); and other (2\%). The respondents' age breakdown was: under 30 years (20\%); 30-40 years (37\%); 40 - 
50 years (36\%); and over 50 years (7\%). Their construction experience breakdown was: 0-5 years (24\%); 610 years (19\%); $11-15$ years $(24 \%) ; 16-20$ years (17\%); and over 20 years (16\%). Evaluating education levels was necessary to demonstrate that the respondents were sufficiently educated to develop a professional opinion about the construction industry. If, for example, there were a high frequency of respondents with only a high school education, the results obtained may carry questionable authority and may not be submissible as an accurate and valid interpretation of the TT process. Fortunately, the highest frequency of respondents had a bachelor degree (61\%). Masters degree qualified respondents were also quite common (28\%), followed by diploma qualifications $(9 \%)$ and doctoral degree (1\%). Unexpectedly, very few respondents had less than a tertiary education in the AEC field (1\%).

\section{TT project profile}

Respondents were requested to detail the number of projects they have been involved with where TT was incorporated. More than half of the questionnaire participants have been involved with at least two past projects involving TT. Only one third of the sample has been involved in just one international TT project. This gives them a good basis for evaluating the importance and success of individual TT process and outcome variables. Understandably, very few respondents (about 6\%) participated in more than ten international TT projects, since planned TT is a relatively new concept in the Thai construction sector. Respondents were requested to provide a range of information on the last three construction projects they have been involved in where TT from a foreign partner was integrated. In total, the respondents provided detailed information on 280 projects constructed in Thailand. The information collected for these projects included year completed, project description, project value, transferor nationality, skills transferred, mode of transfer and a general rating on the success of the project. A descriptive summary for each of these items is provided in the following paragraphs.

The primary mode of transfer for construction projects where TT was implemented was joint venture (39\%), closely followed by turnkey (37\%). This trend reinforces other studies reported in the literature (Calantone et al., 1990). Management contracting was the next highest mode of transfer $(23 \%)$ followed by other modes of 
transfer (1\%). Additionally, the nationality of the technology transferor (i.e. foreigner) for each of the 280 listed projects was requested. Japan were involved in the highest numbers of projects (37\%), followed by Germany (21\%), USA (16\%), other countries (15\%), United Kingdom (8\%) and Australia (3\%). Other transferor nationalities included French, Taiwanese, Chinese, and Danish, to name a few. This result confirms comments made by Raferty et al. (1998) which describes Japan as an international leader in the provision of construction services.

There were four groupings of skills transferred during the TT process including management, technical, new technology and other. Technical skills were predominately transferred $(43 \%)$, followed by management and new technology skills, both being transferred on 27 per cent of the projects. Skill types other than those previously mentioned (e.g. research and development) were transferred on only three per cent of the projects. Most projects examined transferred more than three types of skill. To gain a very general idea on the success of TT on individual projects the respondents were requested to provide a rating from very low (1) to very high (5). The majority of projects were rated as having moderate to high success (86\%) with only 11 per cent indicating a low success rating.

The type of projects undertaken for specific time periods was examined and the results were classified into five main categories: residential building; commercial building; industrial building; civil engineering project; and transportation infrastructure. Listed projects completion dates were grouped into five-year categories from 1970 till 2010. In recent years (2000-2005), a high number of transportation infrastructure and civil engineering projects were constructed in Thailand. This highlights that most construction technology was transferred on the large-scale infrastructure projects with a value greater than 2000 million Thai Baht (approx. US\$50 million). In this study it was found that technology was rarely transferred to the less complex residential construction sector over the last 30 years in Thailand. This may be due to the competitive nature of this sector and the reduced desire of local contractors to enhance their skills. 


\section{Data Analysis and Results}

\section{Analysis of variance}

Analysis of variance (ANOVA) was performed to ensure that respondents having different positions (e.g. site engineer, consultant, etc.) and from different types of organizations (contractor, consultant, etc.) could be considered as a single sample. ANOVA confirmed congeners between position types at the 0.05 level of significance (Black et al., 2000). However, for the type of organization, there were two variables, namely, willingness to implement $(p=0.022)$ and financial performance $(p=0.002)$, which had a significantly $(p<$ 0.05) different mean value for two organization types (main contractor, sub-contractor). Carefully examining mean values for these variables within their respective groups, it appears that sub-contractors do not believe that TT is being transferred to their level and has no bearing on their financial performance. It should be noted that international TT typically involves only the larger contractors and consultants, thus many subcontractors perceive that TT will not generate any value for them. Since this variance was not widespread and only resulted in two combinations the data was treated as one useable sample.

\section{Rating TT variables}

As previously described, the questionnaire respondent was required to rate their opinion for 29 items on a 5point Likert scale for two different aspects (column A: importance/significance; and column B: success/effectiveness). Table 2 details the mean and standard deviation value (columns A \& B) for each variable in the conceptual model. The significant outcomes of this analysis are summarized below:

- The mean values for all variables in column A were greater than three (3.0) indicating that respondents perceived that the entire set of variables contained in the questionnaire were important.

- Transferor characteristics (3.97) were considered to be the most important TT process enabler. However, transferee characteristics (3.93) and the learning environment (3.84) were also considered almost equally important. Perhaps due to respondents' limited understanding on the impact of macro 
factors on the TT process, the transfer environment construct (3.44) was not considered to be as important as the others.

- Communication (4.28) was considered to be the most important variable. Surprisingly, involving sub-contractors in the TT process (3.28) and the construction mode of transfer (3.36) were considered the least important enabling variables.

- Most of the TT value creation variables were deemed highly and equally important. Respondents perceived that the implementation of TT programs was essential for improving quality standards (4.01). Since quality standards in developing countries are generally perceived to be quite low this result is not surprising. However, the importance of TT for improving the financial performance of host firms was notably lower (3.47) than the other outcome variables.

- Based on their experience, the respondents rated transferor and transferee characteristics as being the most successful enablers (3.63). Adversely, they thought that the transfer environment was the lowest performing enabler (3.29).

- Communication was not only perceived as the most important variable but was also rated as the most effective (3.92). This result is promising, considering the variety of nationalities involved in TT projects in the Thai construction sector. Dealing with cultural differences had the lowest success value (3.03). It seems that both the transferor and transferee have no problems communicating and working together in a professional environment but failed to (or don't want to) empathies with the other nationalities cultural make-up.

- Overall, the respondents indicated that TT was creating moderate to high value for the host sector. However, they did not believe that TT initiatives were providing substantial contributions to improved financial outcomes (3.24) for their firms.

The variables within all constructs were considered important (i.e. $>3$ ), therefore, a total of 29 variables was utilized for the initial factor analysis computation.

Table 2 TT construct and variables mean and standard deviation

(INSERT TABLE 2) 


\section{Exploratory factor analysis}

Exploratory principal component factor analysis, with varimax rotation, was conducted to condense the information contained in the original 29 variables into a smaller set of factors with a minimum loss of information (Hair et al., 1998; Hatcher, 1994). Specifically, the aim was to search for and define the fundamental constructs assumed to underlie the original variables. The data sample was deemed adequate for factor analysis, exceeding the observation to variable ratio (i.e. 5.6:1) recommended by Hair et al. (1998). Moreover, the value for the Kaiser-Meyer-Olkin measure of sampling adequacy was 0.84 , exceeding the recommended threshold level of 0.5 (Coakes, 2005). Exploratory Factor Analysis (EFA) retained a 20 variable solution, removing a total of 9 variables. Two of the removed variables (i.e. culture and training) had very high loadings within their own individual constructs. These factors could be argued as being essential enablers in the TT process; however, they were removed because they were factors which consisted of only one generic variable. The implications of the removal of these factors are discussed in detail in a later section of this paper.

Eight (8) factors best represented the data in terms of variance explained (77\%) and grouping of variables. These factors included: (1) technology characteristics; (2) government influence; (3) relationship building; (4) transferor characteristics; (5) transferee characteristics; (6) economic advancement; (7) knowledge advancement; and (8) project performance. Table 3 details the factor loading, explained variance, eigenvalues and Cronbach's alpha for the eight-factor solution. All factor loadings exceeded the 0.5 threshold level with loadings ranging from 0.64 to 0.80 . Additionally, Cronbach's alpha results ranged from 0.57-0.86 indicating that the scale used was reliable (Fang et al., 2004; Hatcher, 1994; Zain et al., 2005). The results underline that the transferor characteristics factor is the key enabler of the TT process explaining almost half $(35 \%)$ of the total variance in the data set $(77 \%)$. The combined explained variance for the project-level enablers (i.e. transferor and transferee characteristics, relationship building) equates to more than two-thirds $(53 \%)$ of the total variance $(77 \%)$. These are undoubtedly, the factors that need to be carefully managed to ensure that the TT process derives the most value for the host country. 
The last three of these factors (6-8) are related to the outcomes derived from TT, and each contained only two variables. These factors would be better represented as one broader outcome factor, as originally perceived in the conceptual model (Figure 1). To verify this, factor analysis was performed on these three factors (6 variables). As suspected, only one factor resulted, explaining 55.7 per cent of the variance and all loadings exceeded 0.6 (Table 4). Thus, factor analysis produced an international TT model consisting of six factors, including, five enablers: (1) Technology Characteristics (TC); (2) Government Influence (GI); (3) Relationship Building (RB); (4) Transferor Characteristics (TR); (5) Transferee Characteristics (TE); and one outcome factor: (6) TT Value Added (VA). The following stage of analysis utilizes Structural Equation Modeling (SEM) to confirm the model structure and causal paths between factors.

Table 3 Varimax rotated factor loading for the eight-factor solution

(INSERT TABLE 3)

Table 4 Varimax rotated factor loading for the single outcome factor solution (INSERT TABLE 4)

Structural equation modeling

SEM using AMOS 5.0 software was performed to test the research model and interrelationships between factors. SEM is an effective technique for conceptualizing a theoretical model, confirming relationships between variables and gaining insight into the causal nature and strength of identified relationships (RaguNathan et al., 2004; Zain et al., 2005). However, SEM is a structural technique requiring large samples with a minimum sample size of fifteen (15) cases per measured variable. Since factor analysis reduced the number of variables to six factors, a satisfactory ratio of 27:1 cases per measured variable was achieved (ITS, 2001). Moreover, the developed model needs to satisfy conditions for a number of 'fit' indices. The reader is referred to ITS (2001) for a complete description of these and their threshold acceptance levels. For the purpose of this study, SEM was employed for the following two main tasks: (1) confirmatory factor analysis 
was undertaken to corroborate the six constructs established through exploratory factor analysis (i.e. testing the measurement model); and (2) determining significant causal paths between factors.

\section{Measurement model}

Confirmatory Factor Analysis (CFA) was undertaken to corroborate findings determined through EFA. The measurement model for these six constructs (latent variables) had acceptable goodness-of-fit indices: RMSEA $=0.048$, GFI $=0.90$, CFI $=0.96$, TLI $=0.95$ (Ragu-Nathan et al., 2004; Zain et al., 2005). Moreover, the results indicated that the items used for each factor were representative of that factor (regression weights $>0.5$, significant t-value at the 0.05 level), with some exceptions (Table 5). Variables related to the technology characteristics factor (construct) were problematic. The construction mode of transfer variable had a low regression weight $(0.38)$ whilst the complexity level variable was only marginally significant $(t=1.64, p=0.1)$. Moreover, the regression coefficient for the latter variable was high (1.06) with excessive standard errors evident, indicating multicollinearity. EFA determined that the technology characteristics factor was reliable but provides some hints it could be problematic (Cronbach's $\alpha=0.57$; Variance explained $=3.53 \%$ ). In summary, CFA did not support the retention of the technology characteristics factor and it was removed from the SEM. CFA was again undertaken with the remaining five (GI, RB, TR, TE and VA) factors and their associated variables. The results indicated that the items used for each factor were representative of that factor (regression weights $>0.5$, significant $t$-value at the 0.01 level). The revised measurement model for these five constructs (latent variables) also had acceptable goodness-offit indices: $\mathrm{RMSEA}=0.046, \mathrm{GFI}=0.90, \mathrm{CFI}=0.97, \mathrm{TLI}=0.96$. The revised model was utilized for path analysis in the following section.

Table 5 Measurement model results (INSERT TABLE 5) 
Paths analysis was undertaken using the SEM technique to uncover the significant interrelationships between the factors retained from EFA and CFA. From the analysis it was determined that government influence was the only exogenous $(\gamma)$ factor in the model. The remaining enablers were considered to be endogenous factors $(\beta)$. The causality relations considered are non-recursive. Moreover, discriminate validity analysis did not uncover any correlated endogenous perspective (Anderson and Gerbing, 1988; Kaynak, 2003). Additionally, scatter plots between the five factors were conducted to ensure that a linear trend best represented (i.e. highest $\mathrm{R}^{2}$ fit) their relationship. Figure 2 presents the formulated path model for international TT in construction projects. This model has the following fit coefficients: CMIN/DF $=1.34$, RMSEA $=0.046, \mathrm{GFI}=0.90, \mathrm{AGFI}=0.87, \mathrm{NFI}=0.88, \mathrm{CFI}=0.97, \mathrm{TLI}=0.96$. In total, four structural equations explained the five causal relationships (paths) which exist between the five retained TT enabling and outcome factors. It should be noted that whilst government influence was denoted as a significant predictor $(p<0.05)$ of transferee characteristics $(\mathrm{GI} \rightarrow \mathrm{TE})$ it explained only a fraction of the variance in this factor $\left(R^{2}=0.04\right)$. This may be due to the fact that respondents had widely varied perceptions on the impact of government policy and enforcement, based on their sector-specific experiences. A summary of the developed structural equations, path coefficients and significance levels is provided in Table 6. The following section discusses the practical implications of each structural equation and its' associated predictor variables.

Table 6 Standardized path coefficients and structural equations (INSERT TABLE 6)

Figure 2 Path model for international TT in construction projects (INSERT FIGURE 2) 


\section{SEM Discussion}

Utilizing EFA, CFA and path analysis, a five-factor structural model of international TT was developed. A discussion on each of the four structural equations detailed in Table 6 will be provided as follows:

- Transferee characteristics $\left(Z_{\mathrm{TE}}\right)$ : Government influence was determined to be the only predictor of transferee characteristics. Specifically, if host government creates an environment conducive for international TT they will be more likely to entice local construction firms with the necessary knowledge, experience and management to step up to the construction procurement challenge.

- Transferor characteristics $\left(Z_{\mathrm{TR}}\right)$ : The results confirm that transferee characteristics and government influence can directly promote enhanced transferor characteristics. Achieving success when transferring highly complex technology will be more likely to occur when the transferee has experience working with foreigners, a strong knowledge base on construction technology and their management practices stimulate the technology transfer process. Additionally, the transferee must have a sufficient technology capability maturity before a transferor will see value in dispensing with their knowledge. The government policies of host countries, such as trade agreements, exemptions from tariff/import duty, etc. could strongly encourage international firms to participate in TT projects. Moreover, governments may also help to promote solid relationships by encouraging only those foreign firms that possess agreeable transferor characteristics.

- Relationship building $\left(Z_{\mathrm{RB}}\right)$ : The results confirm that appropriate transferor characteristics are essential for relationship building. Transferors that have experience working with foreigners, a strong knowledge base and are willing to transfer their knowledge will create robust bonds with local workers, which are based on mutual trust, communication and understanding.

- $\quad T T$ value added $\left(Z_{\mathrm{VA}}\right)$ : The results confirm that relationship building is essential for achieving outcomes from the TT process. Governments in several developing countries are currently 
encouraging international TT initiatives in an attempt to improve their industries, living standards and economic prospects. This objective can only be achieved if host workers and professionals perform at a higher level and become more competitive within both the domestic and international market, eventually becoming a competitor of the transferor. Transferor and transferee firms with idealistic characteristics for TT need to be carefully selected to ensure that the host nation has the best chance for receiving the most tacit and implicit knowledge from the process. Moreover, mutual trust developed through effective communication and understanding between the transferee and transferor will greatly enhance the host firms' knowledge advancement, working practices and overall performance over the long-term.

It should be noted that the developed structural equations may not be as accurate when applied in another context (i.e. path coefficients may change when modeling TT initiatives in another countries AEC sector). Whilst the causal relationships should hold true in these different settings, the strength of the relationship will depend on the maturity of the host nation and its construction sector, in relation to the development continuum. Nonetheless, the identified path equations can be used as a tool by governments and construction firms from developing and newly industrialized countries to monitor the TT process and its' generated outcomes for the host sector. Additionally, the core constructs or factors of the model were generically named in design for easy adaptation for utilization in other industry sectors. With some minor modifications to the derived TT enabling and outcome sub-factors presented herein the developed international TT model could be applied to a wide range of industrial settings.

\section{Implications for Construction Sectors in Developing Countries}

Government departments and industries, such as mining, manufacturing and construction are gaining benefits and competitive advantages from the successful implementation of TT initiatives. Coaxing such TT initiatives is the first step to efficiently and effectively transforming or re-engineering traditional construction business processes, and ultimately improving the productivity of the domestic construction industry. However, it is not enough to just expect that TT will naturally occur. The processes which underpin TT 
should be continuously evaluated to ensure that knowledge and skills are being seamlessly absorbed by indigenous workers. This research study has implications for the construction sector of developing and newly industrialized countries attempting to develop and promote an effective TT process in construction projects. The derived international TT model could be utilized to assist government officers in developing countries to better evaluate TT performance. Specifically, TT stakeholders will be interested in the significant pathways to achieving value from the TT process. Understanding the dynamics of such pathways will assist them to better structure TT arrangements and concentrate on the most empowering enablers. This study provides evidence that when construction projects incorporating international TT are established there must be careful selection of both transferee and transferor firm(s). Firms with appropriate characteristics for TT will form solid bonds that are based on trust, understanding and communication. Thus, it is essential that a substantial investment is provided for workshops and other relationship building activities to create these bonds as early as possible in the construction program. In essence, speeding up the TT value creation process is the key to rapidly enhancing industry capacity and competitiveness.

The model is especially important for publicly funded infrastructure where the government is concerned that advanced technologies are being willingly and effectively transferred to local workers and professionals. Moreover, the model could assist multilateral funding agencies, such as the World Bank, which would want to have tools to better monitor the performance of the TT process when they provide loans for the procurement of necessary infrastructure for developing countries. One of the primary objectives of these funding agencies is to actively encourage domestic firms in developing countries to improve the knowledge levels of their workers as well as industry capacity; ultimately leading to improved standards of living for all indigenous people. Finally, the authors suggest that government and construction industries in developing countries should seriously start to invest funds into further developing acquired construction technology and management knowledge. Such funding will ensure that knowledge is perpetually building in domestic firms diminishing the degree of reliance on foreign firms. 


\section{Future Research Directions}

As previously mentioned, two variables with high factor loadings (i.e. culture and training) were removed through the EFA process. Moreover, CFA did not corroborate the inclusion of variables representing the adopted mode of transfer and the nature/complexity of the technology itself. Future research should address the limitations of this research and include factors, with a number of specific variables, which focus on the impact of technology characteristics, mode of transfer, culture and training on the TT process and its outcomes. Firstly, it could be argued that if the technology being transferred is significantly more advanced than the current working practices of the host workers they may not properly understand how and why it was implemented and thus will be unlikely to embrace it on future projects. Secondly, the construction mode of transfer adopted on the project can influence the degree to which TT performs. It could be argued that joint ventures are one of the better vehicles for achieving higher rates of technology diffusion to the host sector because they typically imply a shared management approach. Thirdly, having compatible culture may play a role in achieving effective outcomes from the TT process. Considerable cultural differences could potentially have an impact on a transferors willingness to implement TT initiatives, which will in turn, can create barriers to achieving harmonious relationships. Moreover, culturally blind leadership, where no attention is paid to cultural difference and indigenous approaches may cause conflicts resulting in the disintegration of teamwork. Lastly, imbedding training into the project schedule could also be considered as a key enabler in the TT process. Implementing training sessions into TT agreements should not only foster mutual trust, communication and information sharing between the transferor and transferee, but will more rapidly advance local workers knowledge at the operational, functional and management levels. Certainly, TT programs which are formally planned and managed (i.e. training times allocated, supervision specified, etc.) are more likely to transfer a greater degree of knowledge to the host workers.

\section{Conclusion}

A model was formulated to help both researchers and practitioners to better understand the international TT process in construction projects. The derived structural model consisted of five factors and five paths, 
representing the interrelationships between the four enabling and one outcome factor. Whilst the model provides a clear picture on how to better utilize TT initiatives to create value for developing and newly industrialized countries, some other enablers should also be considered. EFA and CFA provided some indication that factors addressing technology characteristics, mode of transfer, culture, and training could be included in the model and should be investigated in future research. Nonetheless, the findings of this study and the developed international TT model have essential implications for government and enterprise seeking to enhance relationship building mechanisms and rates of transfer.

\section{References}

Anderson, J. C. and D. W. Gerbing, 1988, Structural equation modeling in practice: a review and recommended two-step approach. Psychological Bulletin, 103, 411-423.

Benedetto, C. A. D., Calantone, R. J. and C. Zhang, 2003, International technology transfer: model and exploratory study in the people's Republic of China. International Marketing Review, 20 (4), 446462.

Black, C., Akintoye, A. and E. Fitzgerald, 2000, An analysis of success factors and benefits of partnering in construction. International Journal of Project Management, 18 (6), 423-434.

Calantone, R., Lee, M. T. and A. C. Gross, 1990, Evaluating international technology transfer in a comparative marketing framework. Journal of Global Marketing, 3 (3), 23-46.

Chacko, G. K., 1986, International technology transfer for improved production functions. Engineering Costs and Production Economics, 10 (1), 245-252.

Chua, D. K. H., Kog, Y. C. and P. K. Loh, 1999, Critical success factors for different project objectives. Journal of Construction Engineering and Management, 125 (3), 142-150. 
Coakes, S. J., 2005, SPSS: Analysis without anguish: version 12.0 for Windows, John Wiley \& Sons Australia Ltd., Sydney, Australia.

Devapriya, K. A. K. and S. Ganesan, 2002, Technology transfer through subcontracting in developing countries. Building Research and Information, 30 (3), 171-182.

Fang, D. P., Xie, F., Huang, X. Y. and H. Li, 2004, Factor analysis-based studies on construction workplace safety management in China. International Journal of Project Management, 22 (1), 43-49.

Fisher, T. F. and M. Ranasinghe, 2001, Culture and foreign company's choice of entry mode: the case of the Singapore building and construction industry. Construction Management and Economics, 19 (4), 343-353.

Ganesan, S. and J. Kesley, 2006, Technology transfer: international collaboration in Sri Lanka. Construction Management and Economics, 24 (7), 743-753.

Gilbert, M. and M. Cordey-Hayes, 1996, Understanding the process of knowledge transfer to achieve successful technological innovation. Technovation, 16 (6), 301-312.

Gold, A. H., Malhotra, A. and A. H. Segars, 2001, Knowledge management: an organizational capabilities perspective. Journal of Management Information Systems, 18 (1), 185-214.

Hair, J. F., Anderson, R. E., Tatham, R. L. and W. C. Black, 1998, Multivariate Data Analysis, PrenticeHall, Upper Saddle River, NJ, USA.

Hatcher, L., 1994, A Step-by-Step Approach to Using the SAS System for Factor Analysis and Structural Equation Modeling, SAS Institution Inc, North Carolina, USA. 
ITS, 2001, Structural Equation Modeling using AMOS: An Introduction. The University of Texas at Austin, Texas, USA.

Kaynak, H., 2003, The relationship between total quality management practices and their effects on firm performance. Journal of Operations Management, 21 (4), 405-435.

Kumaraswamy, M. M. and G. B. Shrestha, 2002, Targeting 'technology exchange' for faster organizational and industry development. Building Research and Information, 30 (3), 183-195.

Lin, B. W. and D. Berg, 2001, Effects of cultural difference on technology transfer projects: an empirical study of Taiwanese manufacturing companies. International Journal of Project Management, 19 (5), 287-293.

Makilouko, M., 2004, Coping with multicultural projects: the leadership styles of finish project managers. International Journal of Project Management, 22 (5), 387-396.

Malik, K., 2002, Aiding the technology manager: a conceptual model for intra-firm technology transfer. Technovation, 22 (7), 427-436.

Marton, K., 1986, Multinationals, Technology and Industrialization, Lexington, MA, USA.

Ofori, G., 2000, Globalization and construction industry development: research opportunities. Construction Management and Economics, 18 (3), 257-262.

Raftery J., Pasadilla B., Chiang Y. H., Hui, E. C. M. and B-S. Tang, 1998, Globalisation and construction industry development: implications of recent developments in the construction sector in Asia. Construction Management and Economics, 16 (1), 729-737. 
Ragu-Nathan, B. S., Apigian, C. H., Ragu-Nathan, T. S. and Q. Tu, 2004, A path analytic study of the effect of top management support for information systems performance. Omega, 32 (6), 459-471.

Saad, M., Cicmil, S. and M. Greenwood, 2002, Technology transfer projects in developing countries furthering the project management perspectives. International Journal of Project Management, 20 (8), 617-625.

San, M. M., 2004, Technology transfer a need for development of building sector. The Myanmar Times. Available online: http://www.myanmar.com/myanmartimes/MyanmarTimes12-235/025.htm (27 September 2004)

Schnepp, O., Von Glinow, M. A. and A. Bhambri, 1990, United States-China Technology Transfer, PrenticeHall, Englewood Cliffs, NJ, USA.

Simkoko, E. E., 1992, Managing international construction projects for competence development within local firms. International Journal of Project Management, 10 (1), 12-22.

Wang, P., Tong, T. W. and C. P. Koh, 2004, An integrated model of knowledge transfer from MNC parent to China subsidiary. Journal of World Business, 39 (2), 168-182.

Williams, F. and D. Gibson, 1990, Technology Transfer: A Communication Perspective, Sage Publications, Beverly Hills, California, USA.

Zain, M., Rose, R. C., Abdullah, I. and M. Masrom, 2005, The relationship between information technology acceptance and organizational agility in Malaysia. Information \& Management, 42 (6), 829-839. 
Table 1 TT process enabling and value creation factors and variables

Table 2 Construct and variable mean and standard deviation

Table 3 Varimax rotated factor loading for the eight-factor solution

Table 4 Varimax rotated factor loading for the single outcome factor solution

Table 5 Measurement model results

Table 6 Standardized path coefficients and structural equations

Fig. 1 Conceptual model for international TT in construction projects

Fig. 2 Path model for international TT in construction projects 
Table 1 TT process enabling and value creation factors and variables

\begin{tabular}{|c|c|c|}
\hline Factors & Description of variables & References \\
\hline $\begin{array}{l}\text { Enablers } \\
\text { Transfer } \\
\text { environment }\end{array}$ & $\begin{array}{l}\text { Complexity of construction technology } \\
\text { Mode of transfer } \\
\text { Government policy } \\
\text { Government enforcement }\end{array}$ & $\begin{array}{l}\text { Calantone et al., 1990; Ganesan and } \\
\text { Kesley, 2006; Kumaraswamy and Shrestha, } \\
\text { 2002; Ofori, 2000; Simkoko, } 1992\end{array}$ \\
\hline $\begin{array}{l}\text { Learning } \\
\text { environment }\end{array}$ & $\begin{array}{l}\text { Culture } \\
\text { Trust } \\
\text { Understanding } \\
\text { Communication } \\
\text { Commitment } \\
\text { Teamwork } \\
\text { Training } \\
\text { Local sub-contractors } \\
\text { Supervision }\end{array}$ & $\begin{array}{l}\text { Black et al., 2000; Devapriya and Ganesan, } \\
\text { 2002; Fisher and Ranasinghe, 2001; } \\
\text { Ganesan and Kesley, 2006; Kumaraswamy } \\
\text { and Shrestha, 2002; Lin and Berg, 2001; } \\
\text { Malik, 2002; Simkoko, 1992; Wang et al., } \\
2004\end{array}$ \\
\hline $\begin{array}{l}\text { Transferor } \\
\text { characteristics }\end{array}$ & $\begin{array}{l}\text { Willingness to implement } \\
\text { Degree of experience } \\
\text { Transferor management } \\
\text { Knowledge base }\end{array}$ & $\begin{array}{l}\text { Benedetto et al., 2003; Fisher and } \\
\text { Ranasinghe, 2001; Ganesan and Kesley, } \\
\text { 2006; Kumaraswamy and Shrestha, 2002; } \\
\text { Lin and Berg, 2001; Makilouko, 2004; } \\
\text { Malik, 2002; Wang et al., } 2004\end{array}$ \\
\hline $\begin{array}{l}\text { Transferee } \\
\text { characteristics }\end{array}$ & $\begin{array}{l}\text { Willingness to learn } \\
\text { Degree of experience } \\
\text { Transferee management } \\
\text { Knowledge base }\end{array}$ & $\begin{array}{l}\text { Benedetto et al., 2003; Fisher and } \\
\text { Ranasinghe, 2001; Ganesan and Kesley, } \\
\text { 2006; Kumaraswamy and Shrestha, 2002; } \\
\text { Lin and Berg, 2001; Makilouko, 2004; } \\
\text { Malik, 2002; Saad et al., 2002; Wang et al., } \\
2004\end{array}$ \\
\hline $\begin{array}{l}\text { Value creation } \\
\text { Economic } \\
\text { advancement }\end{array}$ & $\begin{array}{l}\text { Competitiveness } \\
\text { Performance }\end{array}$ & Benedetto et al., 2003 \\
\hline $\begin{array}{l}\text { Knowledge } \\
\text { advancement }\end{array}$ & $\begin{array}{l}\text { Improved knowledge } \\
\text { Improved working practices } \\
\text { Long-term adoption of transferred skills }\end{array}$ & $\begin{array}{l}\text { Gilbert and Cordey-Hayes, 1996; Gold et } \\
\text { al., } 2001\end{array}$ \\
\hline $\begin{array}{l}\text { Project } \\
\text { performance }\end{array}$ & $\begin{array}{l}\text { Financial performance } \\
\text { Schedule performance } \\
\text { Quality performance }\end{array}$ & $\begin{array}{l}\text { Chua et al., 1999; Devapriya and Ganesan, } \\
2002\end{array}$ \\
\hline
\end{tabular}


Table 2 Construct and variable mean and standard deviation

\begin{tabular}{|c|c|c|c|c|c|}
\hline Code & Descriptions & $\begin{array}{l}\text { Mean } \\
\text { Column A }\end{array}$ & $\begin{array}{l}\text { Std. Dev. } \\
\text { Column A }\end{array}$ & $\begin{array}{l}\text { Mean } \\
\text { Column B }\end{array}$ & $\begin{array}{l}\text { Std. Dev. } \\
\text { Column B }\end{array}$ \\
\hline \multicolumn{6}{|c|}{ Enablers } \\
\hline E1 & Transfer Environment & 3.44 & 0.93 & 3.29 & 0.81 \\
\hline E 1.1 & Complexity level & 3.48 & 0.82 & 3.24 & 0.65 \\
\hline E 1.2 & Mode of transfer & 3.36 & 0.84 & 3.36 & 0.74 \\
\hline E 1.3 & Government policy & 3.41 & 1.04 & 3.26 & 0.87 \\
\hline E 1.4 & Government enforcement & 3.49 & 1.00 & 3.29 & 0.98 \\
\hline E2 & Learning Environment & 3.84 & 0.85 & 3.47 & 0.89 \\
\hline E 2.1 & Culture & 3.39 & 1.04 & 3.03 & 0.88 \\
\hline E 2.2 & Trust & 3.92 & 0.83 & 3.44 & 0.91 \\
\hline E 2.3 & Understanding & 3.96 & 0.97 & 3.51 & 1.00 \\
\hline E 2.4 & Communication & 4.28 & 0.81 & 3.92 & 0.88 \\
\hline E 2.5 & Commitment & 3.75 & 0.81 & 3.52 & 0.84 \\
\hline E 2.6 & Teamwork & 4.04 & 0.76 & 3.64 & 0.83 \\
\hline E 2.7 & Training & 4.10 & 0.79 & 3.70 & 0.94 \\
\hline E 2.8 & Local sub-contractors & 3.28 & 0.95 & 3.04 & 0.88 \\
\hline E 2.9 & Supervision & 3.85 & 0.73 & 3.44 & 0.87 \\
\hline E3 & Transferor Characteristic & 3.97 & 0.79 & 3.63 & 0.86 \\
\hline E 3.1 & Willingness to implement & 3.99 & 0.82 & 3.57 & 0.98 \\
\hline E 3.2 & Degree of experience & 4.07 & 0.78 & 3.65 & 0.79 \\
\hline E 3.3 & Transferor management & 3.81 & 0.77 & 3.61 & 0.84 \\
\hline E 3.4 & Knowledge base & 4.01 & 0.77 & 3.67 & 0.83 \\
\hline E4 & Transferee Characteristic & 3.93 & 0.80 & 3.63 & 0.80 \\
\hline E 4.1 & Willingness to learn & 4.07 & 0.85 & 3.72 & 0.83 \\
\hline E 4.2 & Degree of experience & 3.88 & 0.82 & 3.62 & 0.82 \\
\hline E 4.3 & Transferee management & 3.76 & 0.79 & 3.54 & 0.77 \\
\hline E 4.4 & Knowledge base & 4.02 & 0.74 & 3.64 & 0.76 \\
\hline \multicolumn{6}{|c|}{ Value creation } \\
\hline O1 & Economic advancement & 3.95 & 0.77 & 3.55 & 0.83 \\
\hline O 1.1 & Competitiveness & 3.94 & 0.77 & 3.50 & 0.81 \\
\hline O 1.2 & Performance & 3.95 & 0.77 & 3.59 & 0.85 \\
\hline $\mathrm{O} 2$ & Knowledge advancement & 3.87 & 0.76 & 3.46 & 0.88 \\
\hline O 2.1 & $\begin{array}{l}\text { Improved knowledge } \\
\text { Improved working }\end{array}$ & 3.77 & 0.82 & 3.34 & 0.89 \\
\hline O 2.2 & practices & 3.93 & 0.75 & 3.54 & 0.92 \\
\hline O 2.3 & Long-term adoption & 3.92 & 0.71 & 3.49 & 0.84 \\
\hline O3 & Project performance & 3.72 & 0.80 & 3.40 & 0.86 \\
\hline O 3.1 & Financial performance & 3.47 & 0.84 & 3.24 & 0.90 \\
\hline O 3.2 & Schedule performance & 3.69 & 0.79 & 3.44 & 0.81 \\
\hline O 3.3 & Quality standards & 4.01 & 0.77 & 3.52 & 0.86 \\
\hline
\end{tabular}


Table 3 Varimax rotated factor loading for the eight-factor solution

\begin{tabular}{|c|c|c|}
\hline Factor & Items (identifying questions) & Factor Loading \\
\hline $\begin{array}{l}\text { Enablers } \\
\text { 1. Technology Characteristics } \\
\text { Variance }=3.53 \% \\
\text { Eigenvalue }=0.71 \\
\text { Cronbach's } \alpha=0.57\end{array}$ & $\begin{array}{l}\text { Complexity level } \\
\text { Construction mode of transfer }\end{array}$ & $\begin{array}{l}0.80 \\
0.84\end{array}$ \\
\hline $\begin{array}{l}\text { 2. Government Influence } \\
\text { Variance }=5.07 \% \\
\text { Eigenvalue }=1.01 \\
\text { Cronbach's } \alpha=0.81\end{array}$ & $\begin{array}{l}\text { Government policy } \\
\text { Government enforcement }\end{array}$ & $\begin{array}{l}0.90 \\
0.88\end{array}$ \\
\hline $\begin{array}{l}\text { 3. Relationship Building } \\
\text { Variance }=9.87 \% \\
\text { Eigenvalue }=1.97 \\
\text { Cronbach's } \alpha=0.79\end{array}$ & $\begin{array}{l}\text { Trust } \\
\text { Understanding } \\
\text { Communication }\end{array}$ & $\begin{array}{l}0.69 \\
0.75 \\
0.71\end{array}$ \\
\hline $\begin{array}{l}\text { 4. Transferor Characteristics } \\
\text { Variance }=34.97 \% \\
\text { Eigenvalue }=6.99 \\
\text { Cronbach's } \alpha=0.86\end{array}$ & $\begin{array}{l}\text { Willingness to implement } \\
\text { Transferor's degree of experience } \\
\text { Transferor management } \\
\text { Knowledge base }\end{array}$ & $\begin{array}{l}0.64 \\
0.76 \\
0.79 \\
0.72\end{array}$ \\
\hline $\begin{array}{l}\text { 5. Transferee Characteristics } \\
\text { Variance }=8.52 \% \\
\text { Eigenvalue }=1.70 \\
\text { Cronbach's } \alpha=0.77\end{array}$ & $\begin{array}{l}\text { Transferee's degree of experience } \\
\text { Transferee management } \\
\text { Knowledge base }\end{array}$ & $\begin{array}{l}0.84 \\
0.69 \\
0.65\end{array}$ \\
\hline $\begin{array}{l}\text { Value Creation } \\
6 . \text { Economic Advancement } \\
\text { Variance }=6.55 \% \\
\text { Eigenvalue }=1.31 \\
\text { Cronbach's } \alpha=0.83\end{array}$ & $\begin{array}{l}\text { Competitiveness } \\
\text { Performance }\end{array}$ & $\begin{array}{l}0.83 \\
0.79\end{array}$ \\
\hline $\begin{array}{l}\text { 7. Knowledge Advancement } \\
\text { Variance }=4.47 \% \\
\text { Eigenvalue }=0.89 \\
\text { Cronbach's } \alpha=0.77\end{array}$ & $\begin{array}{l}\text { Improved knowledge } \\
\text { Improved working practices }\end{array}$ & $\begin{array}{l}0.82 \\
0.69\end{array}$ \\
\hline $\begin{array}{l}\text { 8. Project Performance } \\
\text { Variance }=4.34 \% \\
\text { Eigenvalue }=0.87 \\
\text { Cronbach's } \alpha=0.70\end{array}$ & $\begin{array}{l}\text { Financial performance } \\
\text { Schedule performance }\end{array}$ & $\begin{array}{l}0.77 \\
0.80\end{array}$ \\
\hline
\end{tabular}


Table 4 Varimax rotated factor loading for the single outcome factor solution

\begin{tabular}{lll}
\hline Factor & Items (identifying questions) & Factor Loading \\
\hline Value creation & & \\
1. TT value added & Competitiveness & 0.78 \\
Variance $=55.71 \%$ & Performance & 0.81 \\
Eigenvalue $=3.34$ & Improved knowledge & 0.74 \\
Cronbach's $\alpha=0.84$ & Working practices & 0.76 \\
& Financial performance & 0.71 \\
& Schedule performance & 0.68 \\
\hline
\end{tabular}


Table 5 Measurement model results

\begin{tabular}{|c|c|c|c|}
\hline $\begin{array}{l}\text { Factor } \\
\text { Variable Description }\end{array}$ & $\begin{array}{l}\text { Standardized } \\
\text { Regression } \\
\text { Weight }\end{array}$ & $t$-value & $R^{2}$ \\
\hline \multicolumn{4}{|l|}{ Technology Characteristics } \\
\hline Complexity level & $1.06^{N S}$ & 1.64 & 1.12 \\
\hline Construction mode of transfer & $0.38^{N S}$ & - & 0.15 \\
\hline \multicolumn{4}{|l|}{ Government Influence } \\
\hline Government policy & 0.74 & - & 0.55 \\
\hline Government enforcement & 0.93 & 5.54 & 0.86 \\
\hline \multicolumn{4}{|l|}{ Relationship Building } \\
\hline Trust & 0.69 & 8.97 & 0.47 \\
\hline Understanding & 0.86 & - & 0.73 \\
\hline Communication & 0.73 & 9.65 & 0.54 \\
\hline \multicolumn{4}{|l|}{ Transferor Characteristics } \\
\hline Willingness to implement & 0.81 & 10.54 & 0.66 \\
\hline Transferor's degree of experience & 0.78 & 10.07 & 0.61 \\
\hline Transferor management & 0.77 & - & 0.59 \\
\hline Knowledge base & 0.77 & 9.90 & 0.59 \\
\hline \multicolumn{4}{|l|}{ Transferee Characteristics } \\
\hline Transferee's degree of experience & 0.67 & - & 0.45 \\
\hline Transferee management & 0.79 & 7.81 & 0.63 \\
\hline Knowledge base & 0.72 & 7.38 & 0.52 \\
\hline \multicolumn{4}{|l|}{ TT Value Added } \\
\hline Competitiveness & 0.65 & - & 0.43 \\
\hline Performance & 0.68 & 9.56 & 0.46 \\
\hline Improved knowledge & 0.65 & 6.26 & 0.42 \\
\hline Working practices & 0.74 & 6.92 & 0.54 \\
\hline Financial performance & 0.62 & 6.23 & 0.38 \\
\hline Schedule performance & 0.57 & 5.79 & 0.32 \\
\hline
\end{tabular}

- Fixed for estimation; NS: Not significant. 
Table 6 Standardized path coefficients and structural equations

\begin{tabular}{lllll}
\hline Paths & Structural equations & Coefficient & $t$ & $R^{2}$ \\
\hline $\mathrm{GI} \rightarrow \mathrm{TE}$ & $Z_{T E}=0.19\left(Z_{G I}\right)$ & $\gamma=0.19$ & $1.92^{* *}$ & 0.04 \\
$\mathrm{GI} \rightarrow \mathrm{TR}$ & $Z_{T R}=0.28\left(Z_{G I}\right)+0.70\left(Z_{T E}\right)$ & $\gamma=0.28$ & $3.72^{* * *}$ & 0.64 \\
$\mathrm{TE} \rightarrow \mathrm{TR}$ & & $\beta=0.70$ & $6.95^{* * *}$ & \\
$\mathrm{TR} \rightarrow \mathrm{RB}$ & $Z_{R B}=0.81\left(Z_{T R}\right)$ & $\beta=0.81$ & $7.65^{* * *}$ & 0.65 \\
$\mathrm{RB} \rightarrow \mathrm{VA}$ & $\mathrm{Z}_{\mathrm{VA}}=0.66\left(Z_{R B}\right)$ & $\beta=0.66$ & $5.15^{* * *}$ & 0.44 \\
\hline
\end{tabular}

$* * p<0.05 ; * * * p<0.01$. 


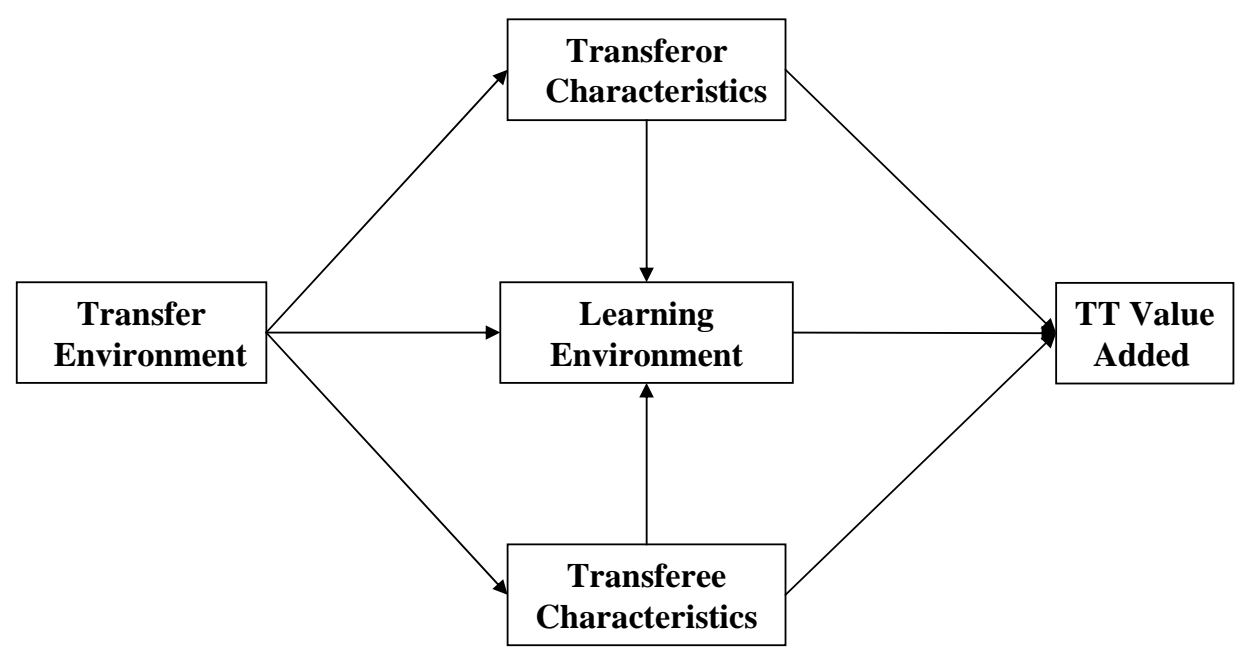

Fig. 1 Conceptual model for international TT in construction projects

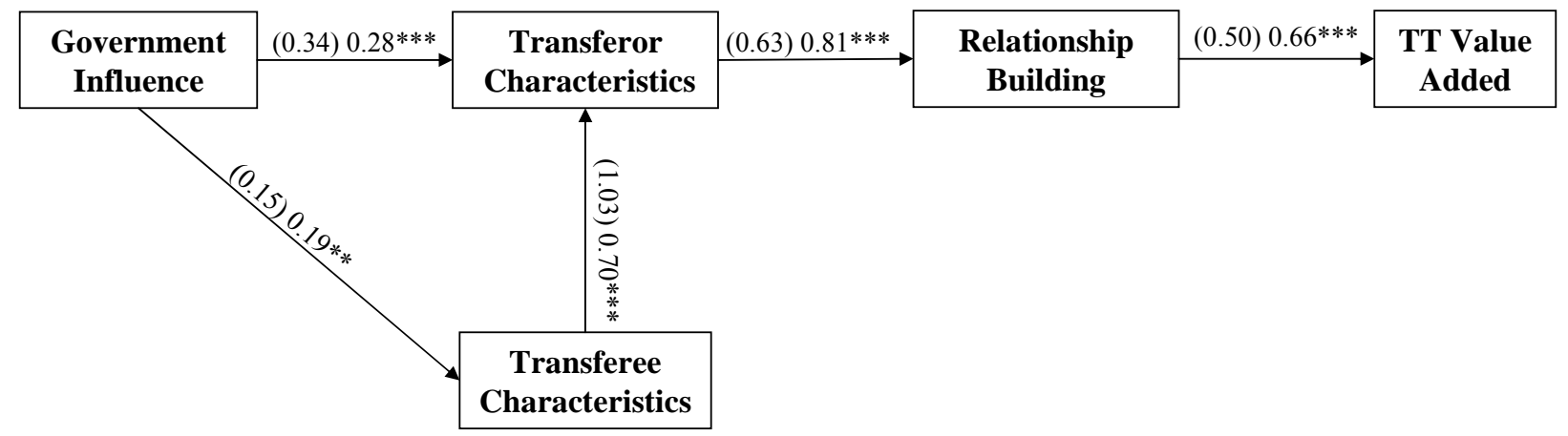

Note: Value in parentheses are unstandardized path coefficients, values not in parentheses are standardized path coefficients. $* * \mathrm{p}<0.05 ; * * * \mathrm{p}<0.01$.

Fig. 2 Path model for international TT in construction projects 